Universidad Nacional de La Plata.

Facultad de Humanidades y Ciencias de la Educación.

Centro de Historia Argentina y Americana

\title{
Composición, salarios y promoción social en el servicio doméstico rural de la Galicia interior, 1700-1825
}

\author{
Composition, Wages and Social Promotion in Rural Domestic \\ Service of inland Galicia, 1700-1825
}

Isidro Dubert *

* Universidad de Santiago de Compostela, Galicia, Españal isidro.dubert@usc.es

\section{Palabras Clave}

Criados

Criadas

Clero

Salarios

Movilidad social

Movilidad geográfica

Galicia

Siglo XIX

Siglo XVIII

KEYWORDS

Servants

Maids

Clergy

Wages

Social mobility

Geographical mobility

Spain

Galicia

\section{RESUMEN}

Gracias al manejo de la información contenida en un variado elenco de fuentes, estudiaremos las características, composición, salarios y promoción social de los integrantes del servicio doméstico rural. Para ello, tomaremos como ejemplo lo sucedido a los criados que trabajaron en los hogares del clero secular de la Galicia interior. Un área geográfica donde se encontraban radicados sus principales mercados de trabajo en el noroeste de la Península Ibérica, tal y como lo prueba el hecho de que a mediados del siglo XVIII de un 8 a un $10 \%$ del total de su población se encontrase empleada en el oficio. Sobre esta base nos acercaremos, entre otras cuestiones, a la consideración laboral y social de los criados, a su relativa capacidad para tomar y dejar empleos, a su grado de movilidad geográfica o a las posibilidades que el servicio doméstico ofrecía a las mujeres para promocionarse socialmente.

\section{ABSTRACT}

We will study characteristics, composition, wages and social promotion of rural domestic service. For this, we will use the servants who worked in the households of the secular clergy of inland Galicia. In this area were located their main labour markets, since in 1752 between 8-10 \% of the total population of inland Galicia was employed in this trade. On this basis, we will approach to work environment of rural domestic service, social consideration of the servants, their internal hierarchy and their relative capacity to take and leave jobs, their degree of geographical mobility or the possibilities that this trade offered to women for their social promotion. 
La Galicia interior, cuyo corazón estaba formado por los territorios del obispado de Lugo, constituye aproximadamente una quinta parte de la Galicia actual y en los siglos XVIII y XIX acogía en su seno a un 23-24 \% del total de la población gallega. Era un ámbito geográfico muy poco urbanizado, visto que hasta bien entrado el siglo XX solo contó con la presencia de dos enclaves urbanos: Lugo, capital provincial, sede episcopal y residencia privilegiada de los grupos sociales rentistas laicos y eclesiásticos, y un poco más al sur, la pequeña la villa de Monforte de Lemos (mapa 1, infra). En uno y otro caso, las comarcas rurales que los enmarcaban se caracterizaban por estar muy poco pobladas -con densidades que a mediados del siglo XVIII rondaban los 26-27 habitantes por $\mathrm{km}^{2}$-,y la existencia de un poblamiento disperso, formado por pequeñas aldeas alejadas entre sí, la suma de las cuales daba vida a las distintas parroquias de la zona (Sobrado Correa 2001b, pp. 27-63; Dubert 1992 , pp. 13-24). En este mundo, alrededor de un $10 \%$ del total de los hogares estaba encabezado por curas e hidalgos. Un porcentaje de relativa importancia, puesto que en el conjunto de Galicia esos hogares apenas si eran un 4,4 \% del total, mientras que en los territorios del sudoeste que miran a las rías, a duras penas conseguían llegar a ser un $2 \%$ del total.

La elevada presencia de familias hidalgas en la Galicia interior de 1752 -un $7 \%$ del total frente por ejemplo al 0,4 \% del mencionado sudoeste gallego-, va de la mano del número de hogares encabezados por un miembro del clero secular -un $3 \%$ del total frente al 1,5\% de ese mismo sudoeste. De algún modo, estas cifras nos indican que la Galicia interior fue un área caracterizada por poseer una elevada concentración de grupos sociales de privilegiados que, en lo básico y bajo las más variadas formas, vivían de la detracción de la renta campesina. Aunque una idea más clara de esa concentración nos la hacemos al decir que el 47 \% de todos los hidalgos y el 27 \% de todos los integrantes del clero secular, registrados en Galicia en el Censo de Floridablanca de 1787, afirmaban residir en un marco geográfico que, como se ha apuntado, apenas si era un $24 \%$ de la Galicia actual.

Esta querencia de las elites por el interior gallego se explica, entre otras razones, por la sistemática utilización que hicieron a lo largo del Antiguo Régimen, de un sistema hereditario no igualitario de corte patrilocal que, tras haberse gestado en los siglos XVI y XVII, alcanzó su plena madurez en la primera mitad del siglo XVIII (Sobrado Correa, 2001b, pp. 96-125; Saavedra, 2002, p. 402). Conforme al mismo, a su muerte, el cabeza de familia solía dejar el grueso del patrimonio familiar al primogénito varón casado en casa, quien por su parte asumía la responsabilidad de casar a sus hermanas y de situar, siempre que ello fuese posible, a sus hermanos fuera del hogar.

En lo que nos atañe, dos son las consecuencias que van a derivarse del empleo de este modelo de reproducción social. Por un lado, la estrecha vinculación de la hidalguía con la Iglesia, merced a la entrada en religión de una parte significativa de sus segundones. Al respecto, un estudio sobre la lógica sucesoria desarrollada por 10 casas hidalgas de la Galicia interior a lo largo de la edad moderna nos indica que entre los mencionados segundones el celibato alcanzaba cotas del $90 \%$, $36 \%$ de los cuales ingresaba en las filas del clero secular, mientras que entre las mujeres de la misma condición ese celibato era solo de un 40 \% (Presedo Garazo, 2009). Por otro lado, también nos indica la importancia que las familias complejas llegaron a alcanzar en la zona -en buena medida, debido a la convivencia en el hogar paterno del hijo casado, su mujer y la descendencia de ambos, junto a los hermanos y hermanas solteros, más aún, toda vez que el sistema hereditario no igualitario comenzó a ser utilizado sistemáticamente por los sectores más pudientes del campesinado. Así se explica entonces que entre 1752 y 1860 el 40-45 \% del total de los hogares del obispado de Lugo fuesen complejos, promedio que, sin embargo en el conjunto de la Galicia interior se reducía a un 30-33 \% del total (Sobrado Correa, 2001b, pp. 204-220; Dubert, 1992a , pp. 105-115).

Al igual que en otros ámbitos rurales del norte de España, donde también predominaban las familias complejas como en el País Vasco, Navarra o Cataluña-, entre el campesinado de la Galicia interior, el grueso de las mismas se concentraba en sus elites (Mikelarena, 1997; Roigé i Ventura, 1999; Comas D’Argemir, 1988). Este grupo estaba formado por aproximadamente el $30 \%$ del total de los hogares, los cuales controlaban el $80 \%$ de la tierra cultivada, que era trabajada gracias a una desigual combinación de mano de obra familiar, criados y jornaleros agrícolas, estos últimos contratados de manera ocasional para las tareas de la cosecha y la recolección. Frente a 
esta minoría de privilegiados, un 44 \% de las familias sobrevivía merced al trabajo realizado sobre el 20 \% de las restantes tierras de cultivo. Las dimensiones de sus explotaciones agrícolas apenas llegaban a las dos hectáreas de tamaño medio, si bien, en realidad, algo más de la mitad tenían menos de una hectárea, motivo por el cual sus titulares se veían obligados a buscar ingresos complementarios con el cultivo del monte por rozas, con el pastoreo de ganado, con el desempeño de los más variados oficios de carácter artesanal y con la emigración estacional y temporal a Castilla. Pero peor suerte tenía ese $16 \%$ de hogares encabezados por campesinos pobres, viudas y solteras, que carecían de tierras y, la mayoría de ellos, de piezas de ganado (Sobrado Correa, 2001b, pp. 206-220; Presedo Garazo, 1999, pp. 256-260)

Como puede apreciarse, alrededor del 40 \% de los hogares de la Galicia interior vivía bien de la percepción de las más variadas rentas campesinas, -caso de los mencionados curas e hidalgos-, o bien de los beneficios que les reportaba el control y explotación del grueso de la tierra cultivable, -caso de las elites del campesinado-. Frente a ellos se disponía un 60 \% de familias que sobrevivían en unas condiciones materiales bastante duras, esto es, trabajando pequeños lotes de tierra y buscando fuentes de ingresos alternativas en la emigración, el desarrollo de las más variadas actividades complementarias y el servicio doméstico. Este último fue desempeñado por al menos un 8 \% del total de la población, aunque, en la práctica, este porcentaje sería mucho más elevado si pudiésemos referirlo -cosa que las fuentes manejadas no permiten- al número de solteros de ambos sexos de entre 7 y 40 años, puesto que más del 95 \% de los criados eran célibes, y un 55 \% de ellos, mujeres (Dubert, 2005, p.14).

La resolución de las necesidades domésticas y de ostentación social de las familias hidalgas y de los hogares del clero secular, junto a las urgencias laborales y domésticas de las elites del campesinado, constituían su particular mercado de trabajo (mapa 1).

\section{Mapa 1 - Localización geográfica de la Galicia interior y principales mercados de trabajo del servicio doméstico rural en el noroeste peninsular a finales del Antiguo Régimen}

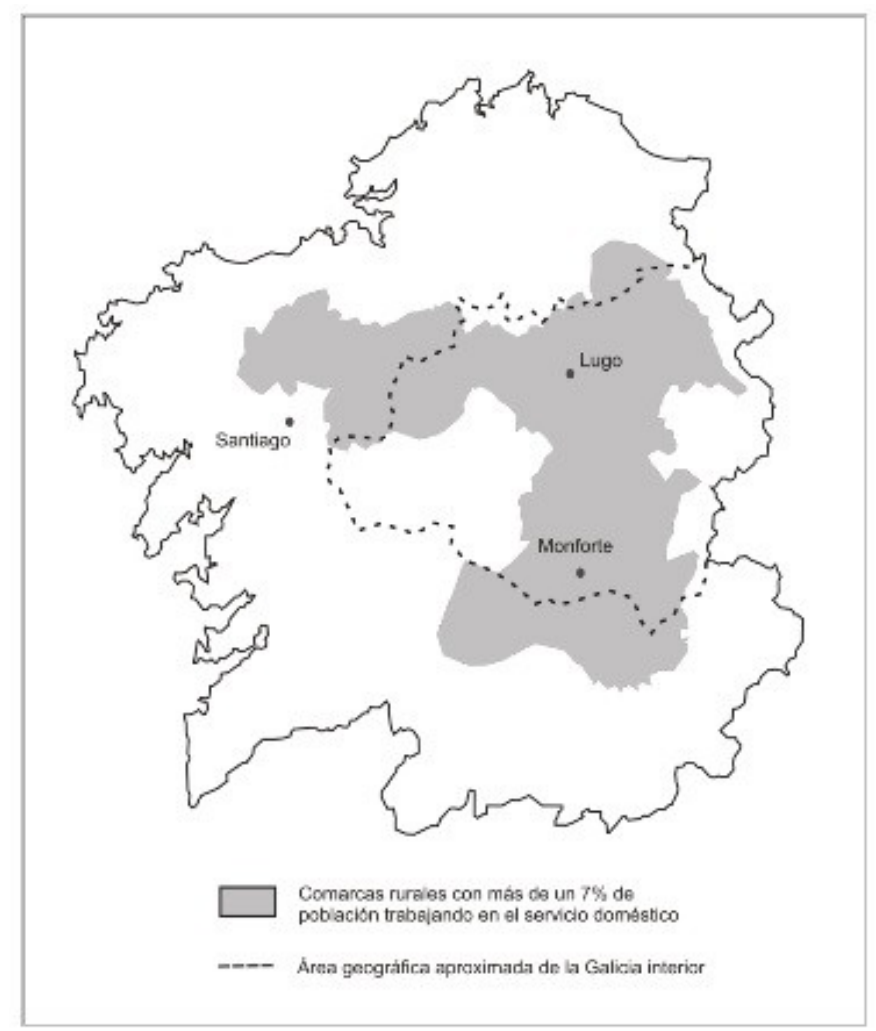

Fuente: Series del Catastro de Ensenada, Archivo Histórico Provincial de Lugo (en adelante A.H.P.L.), Archivo Histórico del Reino de Galicia y en los archivos históricos provinciales de Pontevedra y Ourense.

Elaboración propia. 
Pese a la importancia que en la Galicia del tuvo el servicio doméstico rural, todavía es mucho lo que nos queda por saber de él. Conocemos por ejemplo cuál fue el ritmo que siguió la feminización del oficio, las fases que éste definió hasta su casi total desaparición, el cómo y el porqué del progresivo adelgazamiento y reducción espacial que padecieron sus mercados de trabajo en el tránsito de los siglos XVIII al XIX... (Dubert, 2005, 2009, 2015). Sin embargo, todavía es poco, muy poco, lo que sabemos acerca de quiénes eran realmente los criados, de la relación que mantenían con sus respectivos amos o señores, de la duración de sus contratos laborales, de la jerarquía interna que había entre ellos, o de su capacidad para tomar y dejar empleos.

El descubrimiento de 104 pleitos judiciales abiertos por los criados contra sus señores, -y viceversa-, entre los poco más de 8.600 conservados en el Archivo Histórico Diocesano de Lugo, -todos ellos vistos ante los tribunales civiles y criminales del obispado lucense entre 1700 y 1825-, posibilita el acceso a una fuente de información excepcional para acercarnos al estudio de todas y cada una de estas cuestiones. Una excepcionalidad que deriva de la imposibilidad de encontrar pleitos de naturaleza semejante en los otros archivos de Galicia más que de manera ocasional y aislada. Desde un punto de vista social, la particularidad que los define es la de estar protagonizados por los integrantes del clero secular lucense. Esto nos obligará entonces a estudiar las mencionadas cuestiones a través del comportamiento mostrado por su servicio doméstico. Algo factible, dado que en sus hogares, -recordemos, un $3 \%$ del total de los existentes en la Galicia interior en 1752-, trabajaba el $16 \%$ de todos los criados de la zona, lo que, a nuestros ojos, los convierte en un observatorio ideal para alcanzar los objetivos propuestos.

En esta investigación nos acercaremos primero las características del servicio doméstico rural gracias a la información aparecida en un total de 105 hogares encabezados por miembros del clero secular. La representatividad de los resultados obtenidos por esta vía está garantizada, habida cuenta que en 1755 había en la diócesis de Lugo unos 1.262 eclesiásticos, de los que un 43 \% pertenecían al clero parroquial y el 57 \% restante a las distintas categorías del clero expectante ${ }^{1}$. Esto significa que los 105 casos considerados -seleccionados a partir de la realización de un muestreo aleatorio y sistemático a nivel parroquial sobre el Catastro de Ensenada de 1752-, constituyen el 8,3\% del total de los eclesiásticos lucenses, quienes en un $44 \%$ de las ocasiones eran párrocos y en un 56 \% miembros del clero expectante (tabla $n^{\circ}$ 1). En estas condiciones, el estudio de la información relativa a su servicio doméstico nos ayudará a establecer la composición interna de esta particular fuerza de trabajo, además de permitir aproximarnos a aspectos tales como la importancia que tuvieron los criados en el seno de los hogares del clero secular, o su desigual presencia en los distintos segmentos que le daban vida. En líneas generales, y con las oportunas matizaciones que evidentemente habría que hacer, muchas de las características encontradas serán propias a su vez del servicio doméstico de la hidalguía y de las elites del campesinado (Dubert, 2005).

El manejo de la información recogida por el citado Catastro de Ensenada no nos permite en cambio acercarnos a la naturaleza de las relaciones que los señores mantenían con sus criados, o éstos entre sí. Tampoco nos permite saber nada acerca de la duración de sus contratos laborales, del uso que los criados hacían de sus salarios, de su jerarquía interna o de los factores que incidían sobre el reparto de las tareas domésticas, por ejemplo. Es aquí donde entra en juego el contenido de los pleitos manejados. Gracias al mismo, estamos en condiciones de acceder a sus historias individuales, sociales y laborales, las cuales, no lo olvidemos, estuvieron marcadas históricamente por el peso de los sistemas normativos en los que éstas se desarrollaban. Desde esta perspectiva, es obvio que las situaciones que vivieron y los conflictos en los que se vieron envueltos nuestros criados eran consecuencia de la puesta en marcha, por su parte, de las más variadas estrategias individuales. Su plasmación pondrá de manifiesto, por ejemplo, sus deseos de abandonar un oficio al que sus circunstancias sociales los habían confinado y en cual se verían condenados a permanecer de por vida si fracasaban en su intento de dejarlo. Asimismo, pondrá de manifiesto cómo las relaciones establecidas en el seno de los hogares, sea entre señores y criados o sea entre los mismos criados, se abrían al exterior. Una apertura que nos sitúa ante un mundo laboral que desborda los estrechos muros del hogar, lo que nos permite entrever en él algunos de los mecanismos que los criados empleaban para asumir o cuestionar la identidad social que les había sido asignada por el conjunto de la sociedad de la época (mapa 1). 


\section{Las características del servicio doméstico del clero secular}

En cierto modo, las características del servicio doméstico de la época venían definidas también por la peculiar combinación de la personalidad social y las circunstancias personales del señor. Por este motivo, quizás no estaría de más comenzar este apartado diciendo que los eclesiásticos que estaban al frente de sus respectivos hogares en 1752 tenían una media de edad de 50 años en un mundo en el que la esperanza de vida era de unos 31 (Dopico y Rowland, 1990, pp. 600 y 609) $\underline{2}$. Este hecho los presentaba a los ojos de sus vecinos y feligreses como personas de edad avanzada, que, o bien habían entrado hacía ya tiempo en la vejez, o bien se encontraban en el umbral de la misma. Una situación vital que en parte nos explica que un porcentaje importante de ellos, un $60 \%$ del total, viviese sin ningún miembro de la familia a su lado. Esta soledad, sin embargo, nunca fue completa, ya que en el $65 \%$ de sus hogares siempre hubo, como mínimo, un criado. Lo cierto es que bajo su techo residía una media de cuatro personas $(4,0)$, de las que al menos dos pertenecían al servicio doméstico $(2,0)$, donde las mujeres se imponían a los hombres por un estrecho margen (55\%), mientras que estos últimos superaban los 18 años en tres de cada cuatro ocasiones, información de la que carecemos para las criadas. Con todo, en un $37 \%$ de los hogares manejados trabajaban tres o más criados, lo que nos indica la existencia en su servicio doméstico de una jerarquía interna y de un reparto de funciones que, como en otros lugares de la Europa rural -luego lo veremos-, atendía a criterios tales como el género y la edad.

Tabla 1 - Tamaño y composición de los hogares del clero secular, Galicia interior 1752

\begin{tabular}{|l|l|l|l|l|l|l|}
\hline Tipo de clero & $\begin{array}{c}\text { Distribución } \\
\text { porcentual de } \\
\text { casos }\end{array}$ & $\begin{array}{c}\text { Tamaño del } \\
\text { hogar }\end{array}$ & $\begin{array}{c}\text { Corresidentes } \\
\text { por hogar }\end{array}$ & $\begin{array}{c}\text { Criados por } \\
\text { hogar }\end{array}$ & $\begin{array}{c}\text { \% hogares } \\
\text { con 0 } \\
\text { sirvientes }\end{array}$ & $\begin{array}{c}\text { \% hogares } \\
\text { con + 3 } \\
\text { sirvientes }\end{array}$ \\
\hline Párrocos & 44,0 & 5,0 & 0,9 & 3,1 & 12 & 63 \\
\hline Presbíteros & 46,0 & 3,2 & 1,1 & 1,1 & 47 & 16 \\
\hline Clérigos de Menores & 10,0 & 1,6 & 0,4 & 0,3 & 91 & 9 \\
\hline Total & 100 & 4,0 & 1,0 & 2,0 & 35 & 37 \\
\hline Número de casos & 105 & & & & & \\
\hline
\end{tabular}

Fuente: A.H.P.L., Serie Catastro. Elaboración propia.

Tabla 2 - Servicio doméstico del clero rural, Galicia interior 1752

\begin{tabular}{|l|c|c|c|c|c|}
\hline \multicolumn{1}{|c|}{ Tipo de clero } & $\begin{array}{c}\text { Reparto } \\
\text { porcentual de } \\
\text { los criados }\end{array}$ & \% Criadas & $\begin{array}{c}\text { No declaran } \\
\text { su edad }\end{array}$ & \% Criados & $\begin{array}{c}\text { Mayores de } \\
\mathbf{1 8} \text { años }\end{array}$ \\
\hline Párrocos & 74 & 53 & 90 & 47 & 77 \\
\hline Presbíteros & 25 & 58 & 90 & 42 & 68 \\
\hline Clérigos de Menores & 1 & 67 & 100 & 33 & 0 \\
\hline Total & 100 & 55 & 90 & 45 & 75 \\
\hline Número casos & 203 & & & & \\
\hline
\end{tabular}

Fuente: A.H.P.L., Serie Castastro. Elaboración propia.

La opción de los eclesiásticos de vivir en esa relativa soledad no era una opción de naturaleza religiosa, sino más bien una circunstancia sobre la que pesaban factores de orden económico y social. Y es que de manera semejante a como sucedía en el resto de la sociedad gallega y europea de la época, la presencia o ausencia de personas del interior de los hogares del clero rural, en general, y la de criados, en particular, venía determinada por la posición que uno ocupaba en el interior del estamento. O lo que es igual, por las posibilidades que cada eclesiástico tenía de acceder al uso y disfrute de la riqueza que generaba la titularidad de una parroquia, es decir, la percepción del diezmo, el cobro de las más variadas rentas procedentes del trabajo campesino y los ingresos derivados del ejercicio de la cura de almas. Sobre esta base se explica entonces el diferente tamaño de sus hogares, su distinta 
composición y la desigual presencia de criados en su seno.

Los datos recogidos en las tablas 1 y 2 nos permiten apreciar que las dimensiones de esos hogares y el número de sirvientes que trabajaban en ellos tienden a reducirse a medida que descendemos en la jerarquía interna del clero rural, del mismo modo que lo hace también la posibilidad de contar con criados varones, sobre todo si éstos son mayores de los 18 años. La preferencia que los sectores más bajos del clero secular de la Galicia interior mostraban por las criadas está en relación con el menor costo de su trabajo y contrasta significativamente con lo ocurrido a este nivel en las casas rectorales de los párrocos. Éstos acaparaban al 74 \% de los criados que daban vida al servicio doméstico del clero rural, lo que hacía que en un 88 \% de sus hogares hubiese cuando menos un criado y en un $63 \%$ de ellos, tres o más. Y pese a que entre sus sirvientes se aprecia la existencia de una relativa paridad de sexos, la preferencia que los párrocos manifestaban por tener a sus órdenes criados varones adultos era muy elevada, tal y como nos lo indica el hecho de que éstos superasen la barrera de los 18 años en un 77 \% de las ocasiones. El Catastro de Ensenada poco o nada nos dice en cambio acerca de la edad de las criadas, aunque atendiendo a lo establecido en las constituciones sinodales del obispado de Lugo, es de suponer que todas ellas habrían sido mayores de los 18 años, algo que, como más adelante comprobaremos, la información contenida en las fuentes judiciales desmiente ${ }^{\underline{3}}$.

El reverso de esta imagen la encontraremos entre los integrantes del clero expectante, es decir, entre aquellos que dentro del estamento eclesial se situaban por debajo de los párrocos. En su caso, la carencia de ingresos económicos procedentes de la explotación de una feligresía incidía con fuerza sobre la forma que adoptaba su vida doméstica. Así se explica, por ejemplo, que solo pudiesen contar con el 25 \% del total de los criados que conformaban el servicio doméstico del clero rural. Esto supone que apenas en un $53 \%$ del total de sus hogares había un criado, y en un 16 \% tres o más. De ellos, dos de cada tres eran mujeres y la querencia que mostraban por los varones mayores de los 18 años era más atenuada que la registrada entre los mencionados párrocos (tablas $n^{\circ} 1$ y 2).

Ahora bien, ¿quiénes eran estos criados y qué tipo de relación mantenían con sus amos? Sabemos, a través de la información contenida en la documentación judicial manejada, que un 8 \% del total de los sirvientes que reclamaban ante los tribunales lucenses poseía algún grado de parentesco con el señor para el que trabajaba, mayoritariamente el de sobrino o sobrina. Una condición parental que sin embargo no empañaba su consideración laboral, tal y como reconocía la propia legislación de la época, la cual, al referirse a este tema, es clara y meridiana, haciendo primar siempre la segunda sobre la primera (Febrero, 1806, t. 2, p. 228, n 20 y 21) 4 . Así pues, ni la de legislación de la época ni de la resolución que los jueces otorgaban a estas demandas se desprende que el reclamante fuese considerado como un mero pariente del cabeza de casa, sin más, y sí uno más de sus criados $^{\underline{5}}$. Por su parte, el grueso del servicio doméstico de la Galicia interior, es decir, el $92 \%$ del total sus componentes, mantenía un tipo de relación contractual con sus respectivos señores que no se veía empañada por el parentesco.

\section{Procedencia social, contratos, jerarquía interna y movilidad geográfica}

La entrada de las mujeres en el servicio doméstico se producía a una edad temprana, entorno a los nueve o diez años $\underline{6}$. Es decir, unos cuatro o cinco años antes que en el mundo rural de países como Inglaterra, razón por la cual, como ahora veremos, sus tiempos medios de permanencia en el oficio casi duplican a los conocidos en ese ámbito (Kussmaul, 1981, p. 72 y 79). Quizás en ello haya podido haber influido el hecho de que en la inmensa mayoría de las ocasiones eran mujeres procedentes de los sectores sociales más bajos del campesinado. Este fue el caso por ejemplo de Tomasa López, vecina de la feligresía de san Xoán de Outeiro de Rei, quien en 1723 reconocía haber entrado al servicio de su tío debido a "la suma pobreza de sus padres”르.

La suma de la condición femenina, la falta de medios materiales, las magras ganancias que reportaba el oficio, las escasas expectativas que ofrecía para promocionarse y la baja posición que ocupaban en la escala social, explica 
que las criadas permaneciesen en los hogares largos períodos de tiempo. Cuando menos una media de 11 años, los cuales son fruto de la diferencia entre el momento en que se producía su entrada en el servicio doméstico del clero rural y el inicio de la reclamación contra su señor ante los tribunales, por lo que es posible que, en la práctica, y de no haber aparecido un motivo de enfrentamiento entre ambos, ese período de tiempo hubiese sido mucho mayor. De hecho, sabemos que una de cada cinco criadas estuvo vinculada durante más de veinte años a una misma casa antes de verse obligada a abandonarla a causa de una de estas desavenencias. En suma, para estas mujeres el servicio doméstico era una auténtica forma de vida y no, como en los países del norte de Europa, una mera fase transitoria de la misma. En este terreno, su comportamiento parece haberse situado en un punto intermedio entre lo sucedido en el mundo rural de países como Inglaterra y en las sociedades agrarias radicadas en el extremo sur del continente europeo (Da Molin, 1990, pp. 521, 529; Laslett, 1988; Kussmaul, 1981, p. 72).

La situación de los varones era completamente diferente. Aunque su entrada en escena se producía apenas llegada la adolescencia desde los sectores más humildes del campesinado, lo cierto es que quien los contrataba buscaba en ellos a la persona de un adulto que atendiese al laboreo agrícola de su hacienda. Al respecto, conviene no olvidar que el $75 \%$ de los criados que trabajaban en los hogares del clero rural de la Galicia interior eran "mayores de los dieciocho años" y que su misión era la de "granjear" sus bienes personales, los del iglesario de la feligresía o ambos a la vez (tabla 2).

A pesar de que en la Galicia interior los contratos establecidos entre amos y criados eran verbales -no hemos conseguido hallar ni una sola escritura notarial en este sentido en los archivos de Lugo-, el abandono o el cambio de casa mientras éstos estaban en vigor debía realizarse de mutuo acuerdo entre las partes, ya que, a semejanza de lo ocurrido en otros lugares de Europa, su validez estaba protegida por la ley (Kussmaul, 1981, p. 32; Berkner, 1972, p. 411). Su duración era anual y, en el caso de las criadas, se renovaba de manera automática año tras año hasta que una de las partes se decidía ponerle término. Esto no quiere decir que no hubiese la posibilidad de emplearse por un periodo de tiempo inferior, lo cual era factible, dado que la base real del cómputo del tiempo de

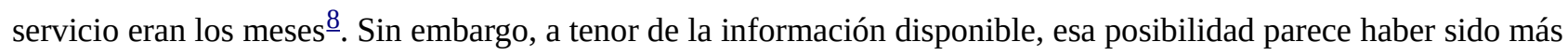
común entre los criados que entre las criadas.

La legislación relativa al servicio doméstico tenía por objeto defender los intereses tanto de la persona que contrataba como del contratado. Así nos lo indican las disposiciones que hacen referencia a la prohibición expresa de que el criado pueda despedirse sin el consentimiento de su señor para emplearse con otro amo $\underline{9}$. Por el contrario, si era el mencionado señor quien lo despachaba sin razón alguna, éste quedaba obligado entonces a efectuarle el pago íntegro de su salario por el período de tiempo que previamente habían acordado (Febrero, 1806, t. 1, p. 237) ${ }^{10}$. Con todo, los criados podían llegar a ver rescindidos sus contratos sin remisión ni pena. El motivo debía revestir una cierta gravedad. Este era el caso del robo o de la mala conducta personal o moral프.

$\mathrm{Al}$ igual que en otras partes de Europa, en la Galicia interior existía una jerarquía interna en el servicio doméstico, dado que no todos los criados desempeñaban las mismas funciones y tareas en el seno del hogar. En primera instancia, en su asignación y definición sexual influía la riqueza de la casa, el tamaño de la hacienda y los patrones locales de cultivo, factores todos ellos de los que dependía además la aparición de un mayor o un menor número de criados, en torno al cual se establecía luego la susodicha jerarquía y reparto de funciones (Bouquet, 1984, p. 143; Johnson, 1984, p. 162). Esto puede apreciarse sin grandes problemas en los hogares del clero secular, visto que un 37 \% de los mismos tenía más de tres criados. En ellos, el género, entendido ahora como una categoría sociolaboral más, demuestra haber sido un elemento estrechamente dependiente de los mencionados factores que influían en la definición y atribución de los roles y tareas que el señor asignaba a los criados y criadas. Para comprender esto, bastaría con decir que en los hogares de las elites del campesinado, por ejemplo, la menor vinculación de las criadas con el trabajo doméstico y su mayor implicación en el desarrollo de las tareas agrícolas se producía a medida que las dimensiones de las explotaciones disminuían y la marcha de las mismas así lo exigía (Lee 1990, p. 54 y ss.; Rey Castelao \& Rial García, 2010, p. 123).

Con esto en mente, y gracias a la información aparecida en casi la mitad de los expedientes judiciales, sabemos 
que el servicio doméstico femenino del clero secular estaba encabezado por las llamadas amas de gobierno, amas de llave o amas mayores, cuya misión era la de "correr con las llaves y el gobierno de la casa”. En ausencia de criados varones, ellas eran quienes debían velar por la salvaguarda de los beneficios de la cosecha y por poner a buen recaudo los frutos, además de organizar las tareas diarias de las criadas de servicio y de las criadas de cocina, las cuales, entre otras cosas, se encargaban de hacer la comida, cocer el pan, lavar la ropa, trabajar como costureras haciendo medias y encajes, hilar el lino con el fin de reparar y reponer las piezas de ropa y menaje pérdidas, y atender a los demás quehaceres del hogar. El peldaño más bajo en esta jerarquía laboral lo ocupaban las llamadas mozas de huerta, cuya tarea básica era, como su propio nombre indica, procurar el cuidado y el granjeo de los huertos $\underline{12}$.

De haber criados varones en la casa, la autoridad del mayordomo estaba entonces por encima de la de las mencionadas amas mayores, ya que atendía a todo lo relativo al gobierno de la hacienda. Es decir, llevaba las cuentas, se preocupaba por cobrar los frutos y las derechuras del curato, por el cultivo y la administración de los bienes, por el cuidado y explotación del ganado mayor y menor, por la obtención de los beneficios derivados de su venta y la del grano, por acudir a los mercados y ferias celebrados en las comarcas vecinas, y por llevar a cabo el control y dirección efectiva de los trabajos asignados a los demás sirvientes $\underline{13}$. En esta escala laboral venían luego los criados de casa, quienes atendían al cuidado personal del amo y a las necesidades materiales del mantenimiento del hogar. Por debajo estaban los llamados criados de labranza, encargados de arar, sembrar y labrar la tierra, cavar el monte, ir a la búsqueda de leña, serrar la madera, traer el estiércol, etc., y por último, los pastores, que atendían y guardaban el ganado, eso sí, siempre al dictado de las órdenes del mayordomo o del señor $\underline{14}$. Con pequeñas variaciones, una jerarquía interna y unas atribución e roles y funciones muy parecida a esta ha sido encontrada también en el servicio doméstico de la hidalguía de la zona (Migués, 2002, pp. 82-87).

El grado de rotación de los criados en los empleos que desempeñaban dependía de su sexo. Como va dicho, las mujeres solían permanecer una media de 11 años con un mismo amo, mientras que entre los varones solo siete de cada diez llegaban a los tres años. Estos últimos gozaban de una gran facilidad para tomar y dejar trabajos. Un buen ejemplo de ello nos lo proporciona Francisco del Real,criado de labranza de 26 años natural de la parroquia de san Miguel de Orbazai. Según su propio testimonio, en agosto de 1782 se empleó como tal criado en una casa del lugar de Felpas, situada a 14 kilómetros de distancia, en la feligresía de santa Mariña de Outeiro de Rei; en agosto de 1783, volvía a Orbazai para trabajar en casa de don José Roa; en febrero de 1784 salía a los campos de Castilla, de donde regresaría a principios de septiembre, y en octubre de 1784 lo veremos ya laboreando en la parroquia de san Xulián de Mons, sita a 20 kilómetros de la citada Orbazai $\underline{15}$. Un periplo laboral que, en última instancia, le habría ayudado a hacerse con el conocimiento de una gran variedad de técnicas agrícolas, las cuales sin duda habrían contribuido a incrementar su grado de cualificación, y con ello, las ganancias que le reportaba el oficio. Por lo demás, como puede verse, y al igual que sucedía en otras comarcas rurales europeas, esta movilidad laboral guardaba una estrecha relación con los ritmos que imponía el calendario de trabajo agrícola (Moriceau, 1994, p. 322; Laslett, 1988, p. 347; Devine, 1984, 1; Berkner, 1972, p. 411; Kussmaul, 1981, p. 4).

A semejanza de lo sucedido en otros países del norte de Europa, los criados de la Galicia interior solían desplazarse a lo largo y ancho de un área geográfica definida por un radio de 5 a 25 kilómetros a partir de su feligresía de origen (Kussmaul, 1981, p. 57). Aunque, a veces, ese radio podía ampliarse y el periplo realizarse mediante una serie de tramos escalonados de longitud más o menos variable. Los desplazamientos realizados en este sentido por Jacinta Quintela en los años previos a 1728 dan buena cuenta de ello, ya que siendo natural de san Pedro de Garabás, trabajó primero en una casa de la parroquia de Carracedo, situada a 30 kilómetros de Garabás; luego, en otra de Santiago de Vilardeortelle, que dista 21 kilómetros de Carracedo; más tarde, en una de santa María de Seteventos, a 11 kilómetros de la anterior; y por último, en una casa de santa María de Tuiriz, a 5 kilómetros de Seteventos; en total, 67 kilómetros lineales recorridos en cuatro empleos diferentes $\frac{16}{}$. Ahora bien, en ocasiones, estos desplazamientos ni siquiera llegaban a los mencionados 5 kilómetros. Esto fue lo que pasó con Gregoria Roxa, vecina de san Salvador das Cortes, quien hasta el día en que se casó continuó sirviendo al mismo 
amo con el que ya en su día había trabajado su madre en la feligresía de san Xoán de Loio, sita a 2,5 kilómetros de distancia de la de Cortes $\frac{17}{}$. Desplazamientos como estos solo podían tener lugar gracias a la existencia de una red de contactos previa, en cuya creación la familia, los parientes, los amigos, los vecinos y los mismos señores, desempeñaban un papel destacado. En otro orden de cosas, nada indica que esta movilidad hubiese generado o alentadoun estilo de vida propio, alternativo, desarrollado en paralelo al trabajo agrícola, que cuestionase las normas sociales básicas por las que discurría el diario acontecer de una sociedad rural como la Galicia interior. Sí en cambio nos remite a la existencia de una intensa micromovilidad en la zona. En ella, se veían involucrados en mayor o menor medida casi uno de cada diez habitantes de la misma en las distintas fases de su vida. No era pues la población de la Galicia interior una población inmóvil, estable, fija a la tierra (Sobrado Correa, 1992, p. 141).

\section{Salarios y soldadas}

No hemos encontrado todavía en Galicia fuentes con las que poder afrontar la reconstrucción de las series salariales anuales del servicio doméstico rural. Al respecto, todo se reduce a referencias aisladas aparecidas en el Catastro de Ensenada de 1752, en las reclamaciones judiciales presentadas por los criados ante la justicia y en los apuntes de algún libro de contabilidad señorial, donde se hacen constar los gastos que el servicio doméstico suponía para la hacienda en este o aquel año (Iglesias Blanco, 2004, pp. 80-81; Migués, 2002, pp. 79-81). Con todo, sabemos que las cantidades en metálico registradas en cualquiera de estos casos no son fiables, ya que, como en el resto de Europa rural, una parte significativa del salario de los criados se pagaba en especies, bajo la consabida forma de alojamiento, comida, ropa o calzado (v.g., Orr, 1984, p. 35; Da Molin 1990, p. 521). Por poner un ejemplo, en 1752, Antonio Rivera, labrador y vecino de la parroquia de Desteríz, en la actual provincia de Ourense, afirmaba tener consigo una criada a quien daba por soldada 44 reales al año y la comida $\underline{18}$. Por su parte, Antonio Galán, vecino de santa María de Pol, en la diócesis de Lugo, recibía en 1742 por su trabajo como criado de labranza nueve reales al año, una camisa de estopa nueva, un calzón de sayal, un jubón de lienzo y seis misas rezadas por su intención, mientras que los criados de la comarca rural del Xallas, situada a unos 30-35 kilómetros al noroeste de la ciudad de Santiago de Compostela, trabajaban por el calzado, el vestido y el equivalente a unos 190 kilos de trigo al año (Barreiro Mallón, 1973, p. 460)ํㅗ․ Pero los problemas para realizar el cálculo aproximado de lo que se les pagaba no terminan aquí, puesto que en la mayoría de las ocasiones al realizar el finiquito salarial, los amos procedían a descontar del montante final los gastos extraordinarios que los criados les habían causado a lo largo de los años de servicio, como por ejemplo, las atenciones médicas.

En esta tesitura, lo único que podemos ofrecer, y siempre a título indicativo, son las variaciones espaciales que muestran algunas de las soldadas que de manera esporádica aparecen recogidas en las parroquias que forman parte del Catastro de Ensenada. Así, sabemos por ejemplo que en 1752 en santa Mariña de Xuño, sita en la actual provincia de A Coruña, los criados de las elites del campesinado cobraban por término medio 114 reales al año; en san Martiño de Ermedelo, también en A Coruña, unos 124 reales, y en san Pedro de Herbogo, unos 150ํㅡ․ Más al sudeste, en la actual provincia de Ourense, en la feligresía de Vilamarín o en la mencionada de Desteríz, los jóvenes de ambos sexos apenas si obtenían 50 reales al año de manos de esas mismas elites, mientras que en la de Santiago de Illán llegaban a ganar unos 132 reales anuales $\underline{21}$. Por otro lado, dentro de todas y cada una de estas comunidades rurales, los distintos grupos sociales desembolsaban salarios diferentes. Lo vemos por ejemplo en la citada parroquia de Xuno, donde las soldadas ofrecidas por el clero secular eran un $18 \%$ más altas que las pagadas por los campesinos, al situarse en torno a los 141 reales al año. Estas disparidades salariales se registran también en el seno de un mismo estamento. Por ejemplo, frente a esos 141 reales anuales a los que acabamos de aludir, en las feligresías de Gaibor y de Illán, pertenecientes ambas a la diócesis de Lugo, -donde el número de individuos dedicados al servicio doméstico era relativamente elevado-, el clero secular apenas si daba a sus criados más que 100 reales al año.

Como en otros contextos europeos, estos salarios variaban en función del sexo, la edad y el cometido laboral asignado (v.g., Kussmaul, 1981, p. 36; Da Molin, p. 1990, p. 521). De ahí que con los datos disponibles 
actualmente nos resulte imposible encontrar en la Galicia rural un patrón de conducta que explique las variaciones salariales a las que hemos aludido, ya que a partir del Catastro de Ensenada nunca sabremos qué tipo de trabajo o de responsabilidades tenían asignadas los criados y las criadas en el interior de los hogares. Es más, ignoramos por ejemplo porqué los criados varones de las elites del campesinado y el clero secular de santa Mariña de Xuño cobraban, respectivamente, una media de 108 y 120 reales, frente a los 131 y 148 reales de las criadas, o también, porqué en la feligresía de Illán los primeros ingresaban 170 reales y las segundas tan solo $116 \underline{\underline{22}}$.

El contenido de los expedientes judiciales atendidos por los tribunales de justicia de Lugo nos permite desvelar en parte esta incógnita. Por ellos sabemos que a lo largo del siglo XVIII, y al margen del tiempo trabajado, en la Galicia interior los salarios más elevados se pagaban a los mayordomos, quienes cobraban una media de 330 reales al año. En orden de importancia venían luego los criados de labranza, con 225 reales; los criados de casa, con 134 reales; las amas mayores, con 116 reales; las criadas de servir, con 109 reales; y las mozas de huerta, con 66 reales. A la vista de esto, y teniendo en cuenta que eran una población mayoritariamente adulta, es evidente que estas diferencias salariales se basaban en el sexo y el cometido laboral asignado. Prueba de ello, es que los salarios de los criados eran un 48 \% más altos que los de las criadas, mientras que la soldada percibida por la categoría masculina más baja del servicio doméstico, los criados de servicio, era un 13 \% más elevada que la pagada a las mujeres que tenían mayores responsabilidades en ese mismo servicio, las amas mayores. Una lógica salarial muy semejante a la registrada en otros ámbitos rurales europeos, solo que aquí las diferencias entre criados y criadas no eran tan acusadas como las encontradas en ellos (Jonhson, 1984, p. 162; Kussmaul, 1981, p. 36).

En estas condiciones, no es difícil entender cómo en la Galicia de la época la asociación secular entre el trabajo doméstico y su baja remuneración económica habría ayudado a configurar y a reforzar determinadas facetas de la identidad femenina. Al fin y al cabo, el trabajo de las criadas se entendía como una mera extensión de las tradicionales tareas desempeñadas por las mujeres en el seno del hogar, amén de poseer una naturaleza supuestamente complementaria a la del trabajo masculino (Sarti, 2015, pp. 196-203; Tilly, Scott, Cohen, 1980, p. 225; Rey Castelao y Rial García, 2010, p. 124). También habría ayudado a ello el hecho de que, como tales mujeres, las criadas no eran independientes, ya que vivían en la casa del amo, sometidas a su tutela y autoridad por períodos de tiempo mucho más largos que los de los criados, quienes iban y venían a su antojo y ganaban salarios mucho más elevados trabajando menos tiempo. Así las cosas, no es fácil interpretar los ascensos o las paulatinas mejoras salariales que puedan haber conocido nuestras criadas como parte de la existencia de una carrera laboral que contribuiría a redimirlas de su miseria material y social. En consecuencia, poco cabría decir de casos como el de Catalina Rodríguez, vecina de san Victorio de Ribas de Miño, cuando allá por 1718 insistía en haber trabajado diez años para el mismo señor: seis como criada de servicio por diez ducados anuales, y cuatro como ama de gobierno por doce $\mathrm{e}^{23}$.

Las demandas salariales constituyen una parte importante de las reclamaciones que los criados realizaban ante los tribunales lucenses. Estas demandas son el 46 \% de los expedientes judiciales manejados y solían abrirse en un plazo de dos a tres años a partir de la finalización de la relación laboral. Se ajustaban de este modo a lo estipulado por la ley, la cual dictaminaba que, transcurridos tres años, el denunciante decaía en su derecho de exigir que se le pagase lo adeudado $\underline{\underline{24}}$. Iniciados los trámites, su resolución solía ser bastante rápida, ya que un $25 \%$ de ellos se sustanciaba antes de los seis meses y otro $25 \%$ entre los seis y los doce meses, superando el $50 \%$ restante el año de duración. Sin embargo, no todas las demandas finalizaban con una sentencia, algo que solo ocurría en dos de cada tres casos. En los demás, los litigantes solían llegar a algún tipo de acuerdo extrajudicial en un período de tiempo que oscilaba entre los siete días y los tres meses desde la apertura del expediente.

Tres cuartas partes de estas reclamaciones fueron efectuadas por criadas. En la mitad de las ocasiones eran amas mayores y en la otra mitad criadas de servicio. En líneas generales, eran mujeres como la hija de Salvador Pérez Gabieiro, vecino de santa María de Pedraza (1778), o como la de María Josefa Blanco, vecina de santa María de san Fiz (1788), quienes comparecían ante la justicia exigiendo el cobro de los salarios atrasados $\underline{25}$. Su impago se debía a los más variados motivos, desde la dejadez y el abandono mostrado por el señor a la hora de cumplir con 
esta obligación hasta su misma insolvencia económica $\underline{26}$.

La realidad a la que se refiere este tipo de reclamaciones es muy dispar, estando reflejada en ella todo tipo de situaciones. Hay causas donde los demandantes exageran el tiempo de servicio y los salarios adeudados. También nos encontramos con la negación por parte de los demandados de conocer, -y por ende de haber tenido trabajando consigo como criado/a-, al reclamante, e incluso a criados que además de los salarios deseaban recuperar los bienes personales que, o bien habían llevado consigo al comienzo de su servicio, o bien habían ido adquiriendo por su cuenta con el correr de los años. Y esto, sin excluir otras muchas situaciones de las que no vamos a ocuparnos ahora. Más interesante nos parece en cambio destacar la capacidad que unas personas con tan pocos recursos y medios materiales tenían para reclamar judicialmente lo que era suyo. Aquellos dineros que mujeres como Catalina Fernández, vecina de san Xulián da Veiga, exigían con evidente enfado en 1793 afirmando que “con el sudor de mi rostro los tengo bien ganados”, o que Antonio Galán, vecino de Pol, reconocían necesitar con cierta urgencia en 1742, porque “mi parte es pobre y vive de su trabajo personal”, $\underline{27}$.

La atención y la rápida resolución de sus demandas por los tribunales fue sin duda uno de los elementos que animó a los criados a desplazarse hasta la ciudad de Lugo para solicitar justicia. No dudaban así en recorrer largas distancias para la época, las cuales han sido calculadas atendiendo a los kilómetros que separaban el lugar en el que decían residir al momento de hacer la mencionada demanda, y el lugar físico donde se ubicaba el tribunal. Apreciamos entonces cómo poco más o menos un tercio de ellos llegaba a la urbe tras haber recorrido una media de 40 a 50 kilómetros desde las feligresías situadas al oeste de la provincia, en la Dorsal Gallega, la zona montañosa definida por el territorio de los actuales municipios de Melide, Palas de Rei, Monterroso, Melide y Toques. Un área cuyos habitantes, sabemos, gozaron de una cultura de la movilidad campo-ciudad construida a lo largo de los siglos XVIII y XIX sobre la base de los sucesivos desplazamientos que realizaron a las ciudades de Santiago de Compostela, A Coruña y Lugo, para trabajar como criados (Dubert, 2001, pp. 157-163). Una cultura que no era inusual en las áreas de montaña europeas de la época, que también fueron un vivero de sirvientes para los enclaves urbanos relativamente próximos a ellas (Salinari, 2004, pp. 55-62). En todo caso, la existencia de esa cultura explica, por un lado, la facilidad que tenían los criados de esta zona para presentarse ante los tribunales lucenses, y por otro, la capacidad de reclamación que poseían frente a sus amos.

\section{Mapa 2 - Lugar de procedencia de los criados que reclamaron el pago de sus soldadas y el cobro de la dote y soldadas ante los tribunales, 1700-1825}

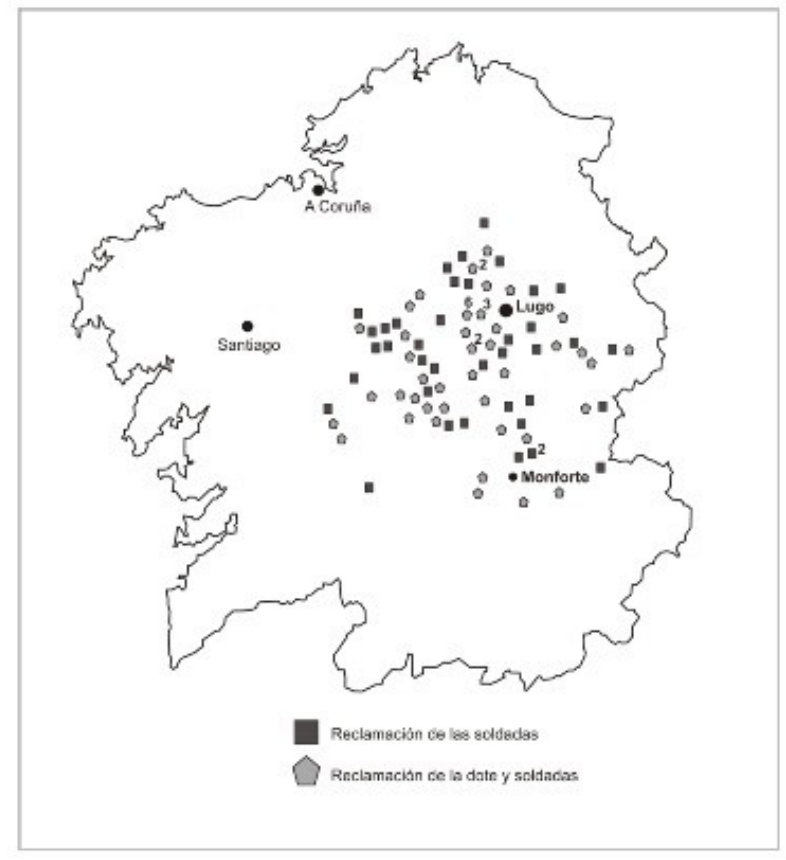

Fuente: A.H.P.L., Fondo de Pleitos Civiles y Criminales. Elaboración propia. 
Algo menos de la mitad de los demandantes procedía en cambio de parroquias dispuestas en un radio de 15 a 20 kilómetros a partir de la ciudad. La cercanía al tribunal es pues una de las razones que nos ayuda a entender la nutrida presencia de criados de este ámbito geográfico ante los jueces. Por último, una cuarta parte de los litigantes viajaba hasta la urbe desde feligresías situadas al sureste, tras recorrer una distancia media de 45-50 kilómetros, desde comarcas dispuestas bien en las Montañas Orientales que lindan con el vecino reino de Castilla o bien en el área premotañosa definida por los actuales municipios de Bóveda, Pobra do Brollon y O Incio. Su escaso peso en el conjunto puede deberse a que era una zona con una economía agrícola pobre, a la difícil comunicación que tenían con Lugo, a la ausencia de tradiciones migratorias campo-ciudad como las registradas entre los habitantes de las parroquias enclavadas en la Dorsal Gallega, o a la combinación de todos y cada uno de estos factores.

\section{La promoción social de las criadas}

En un $54 \%$ de las reclamaciones encontramos a las criadas solicitando, junto al pago las soldadas adeudadas, el desembolso de la dote que el señor les había prometido entregar en el momento de su boda. La información que contienen nos permite atisbar las estrategias que algunas de ellas pusieron en práctica con la intención de dejar atrás el servicio doméstico, las cuales, en casi todos los casos, pasaban por la realización de un matrimonio. De esa información se desprende, además, que esas estrategias se fueron configurando, unas veces, sobre la marcha, a medida que transcurrían los acontecimientos, mientras que, en otras, da la impresión de que fueron diseñadas a partir de la experiencia acumulada por todas aquellas mujeres que en su día habían abandonado el oficio por esta vía.

La reclamación solía efectuarse unos 6-7 años después del desarrollo de los acontecimientos. Como va dicho, el análisis de su contenido nos indica que los pasos conducentes a la demanda de la mencionada dote transcurrían conforme a la existencia de un verdadero modus operandi. El problema es que las fuentes solo nos permiten recomponer una parte del mismo, ya que las criadas suelen presentarse ante el tribunal como víctimas de una solicitación sexual que se vieron forzadas a aceptar, sea por la reiterada insistencia del amo, sea por haber cedido a la tentación de haber aceptado los bienes que éste les ofrecía como dote, o sea por ambas cosas a la vez. Las denunciantes pretendían dar así la impresión de haberse visto envueltas en una situación ante la que no habían tenido ninguna otra salida, pese a que en no pocas ocasiones reconociesen abiertamente haberse refugiado primero en casa de sus padres, de donde, no obstante, acababan saliendo a instancia de los oficios y lisonjas de los alcahuetes enviados por el señor para que se rindiesen a sus deseos. Por esta razón, la actitud resignada y fatalista que impregna su relato de los hechos parece fruto de una estrategia calculada en razón de su condición de mujeres que declaran ante un tribunal señorial dependiente del obispo compuesto por hombres, muchos de ellos clérigos. Un fatalismo que contrasta, y mucho, con la larga espera que hacían hasta al momento, lo que les parecía más oportuno para poner la denuncia, dando de este modo publicidad a un asunto transcurrido hacía ya varios años. Muestra de que la mencionada fatalidad formaba parte de una estrategia destinada a obtener ventaja en sus reclamaciones, la tenemos en las palabras que en 1724 pronuncia María Rosa Fernández, vecina de la feligresía de san Vicente de Argozón, quien pese a haber permanecido ocho meses refugiada en casa de sus padres, después de haber servido a su amo durante un año y ser solicitada por él varias veces, al decir de los testigos, consintió en seguir viéndolo "en todas las ocasiones que se le ofrecía y remediaba”, hasta condescender a sus deseos y volver a ser de nuevo su criada $\underline{28}$.

A tenor de las declaraciones, este tipo de historias comenzaba con la contratación de una joven como sirvienta, a quien, pasado un cierto tiempo, se solicitaba a cambio de la promesa de una suculenta dote o del arreglo de un enlace nupcial con un tercero, cuya misión era la de liberarla de trabajar en el servicio doméstico o de compensarla por la posibilidad de llegar a ser madre soltera. Por esta vía, el señor, un eclesiástico, conseguía gozar de sus favores sexuales, máxime cuando la dote que le ofrecía en estas circunstancias podía llegar a suponer el salario de hasta veinte años de trabajo. Así nos lo indican, por ejemplo, los 2.200 reales con los que fue tentada en 1742 María Fernández, criada de servicio y vecina de san Vicente de Rábade. Es en este contexto que hay que 
entender e interpretar este tipo de declaraciones $\underline{29}$.

De la aceptación de estas propuestas se desprende que eran el camino más rápido, directo y seguro para acceder en el menor tiempo posible a esa dote que permitiría a las criadas ser tomadas en consideración por los jóvenes campesinos que se movían en los mercados matrimoniales locales. Se ahorraban de este modo los sacrificios de largos años de trabajo y esfuerzo, aunque ello fuese a costa de asumir el riesgo de quedarse embarazadas, y dar a luz a una criatura ilegítima. Algo que, por otra parte y desde un punto de vista social, no debía ser demasiado grave en un mundo cuyas tasas de ilegitimidad se caracterizaron por crecer paulatinamente a medida que corría el siglo XVIII, al punto de llegar a afectar a comienzos del siglo XIX a un 9-10\% del total de los bautizados (Dubert, 2015, pp. 60-62). Una ilegitimidad a la que en cierto modo debieron de haber contribuido, visto que el número de reclamaciones de este tipo tendió a multiplicarse por dos, entre la primera y la segunda mitad del siglo XVIII, todo lo contrario de lo ocurrido con las demandas por soldada, las cuales se mantuvieron en un mismo tono durante todo el período de estudio. Sea como fuere, no deja de sorprender la facilidad que estas jóvenes tenían para presentar y ver atendidas sus demandas por los jueces. De ahí que podamos verlas litigando en Lugo, donde una de cada tres llegaba desde las feligresías situadas en los territorios montañosos de la Dorsal Gallega, distantes, como va dicho, unos 40-50 kilómetros. Un tercio largo procedía de comunidades rurales dispuestas en un radio de 15 a 20 kilómetros a partir de la ciudad. Una cada cinco era oriunda, en cambio, de las parroquias sitas en los márgenes de la ruta que salía de Lugo y desembocaba en los valles del sur de la actual provincia lucense, eso sí, todas ellas a más de 25 kilómetros de distancia del tribunal, mientras que una de cada diez jóvenes venía de aldeas enclavadas en las Montañas Orientales, en los territorios de los actuales municipios de Becerrea, As Nogais, Cervantes y Folgoso do Courel. En cualquier caso, y con pequeñas variaciones, una geografía muy similar a la diseñada por las reclamantes del pago de soldadas (mapa 2).

Por otro lado, que ocho de cada diez demandantes fuesen criadas de servicio, cuyo salario era uno de los más bajos de los que se pagaban en el servicio doméstico de la Galicia interior, sigue abundando en la idea de que la aceptación de muchas de estas solicitaciones sexuales habría estado relacionada con la existencia de una estrategia que tenía como fin último lograr una posible promoción personal. Así nos lo induce a pensar también la aparición de denuncias falsas, con declaraciones que demuestran haber sido construidas recurriendo a los mismos tropos que las verdaderas. De ellas podemos hacernos una ligera idea gracias a la realizada por María Arias, vecina de san Vicente do Burgo, quien en abril de 1790 denunciaba al presbítero don Matías Cubeiro bajo la excusa de que durante los catorce meses en que le sirvió, éste había aprovechado para hacerle "distintas ofertas [sexuales], y como la otorgante las rehusase [...] desamparó el servicio retirándose a casa de su madre [...] Aquel, se valió entonces de distintas personas para que la redujesen y que volviese a continuar el servicio como lo hizo. Y prosiguiendo el don Matías en su persuasión, la redujo a que con él tuviese actos venéreos, de los que resultó embarazada”. Sigue luego la narración del nacimiento y muerte de la criatura, y de las demás desgracias y humillaciones padecidas por la joven en los meses que siguieron. Tras un año largo de averiguaciones que sirvieron para establecer la inocencia de don Matías, el tribunal condenaba a María Arias por calumnia. La obligaba entonces a asumir el pago de las costas judiciales y le imponía perpetuo silencio sobre el tema, so pena de ser desterrada para siempre de la jurisdicción $\frac{30}{}$.

Sin embargo, curiosamente, una vez comenzados los autos judiciales, ninguna de las partes en liza parece haber estado demasiado interesada en seguir este tipo de litigios hasta el final. Los unos por el menoscabo que experimentaba su crédito personal al hacerse público el negocio, y las otras por una cuestión meramente económica. De ahí que la mitad de estas demandas no fuesen nunca sentenciadas. Lo habitual era llegar antes a algún tipo de acuerdo extrajudicial, merced al cual la afectada obtenía la dote prometida, las soldadas adeudadas y las demás indemnizaciones convenidas. De este modo se ponía término al asunto lo más rápido posible. Algo preferible al dictado de una sentencia, la cual solía ser contraria a la supuesta inocencia del señor en ocho de cada diez ocasiones, y a la que se llegaba tras más de un año de investigaciones, declaraciones de testigos y reiteradas presencias físicas de los encausados ante jueces y abogados del tribunal lucense. Para evitar los perjuicios derivados de este trajín y ocultar el delito, muchos señores optaban por arreglar matrimonios de conveniencia para 
sus criadas, en los cuales, el montante de los años de servicio y la dote convenida actuaban como banderín de enganche para los posibles candidatos. Así ocurrió con Andrés do Campo, vecino de san Vicente de Rábade, cuando decidió casarse con Gabriela do Vilar, en la declaración realizada ante los tribunales en 1784, dejó claro que en 1780 ya sabía que Gabriela mantenía relaciones con su señor. De hecho, durante su posterior preñazgo, éste la ocultó en la ciudad de Lugo para evitarle problemas con la justicia ordinaria de la zona. Tras el nacimiento de la criatura, Gabriela volvería a su servicio, si bien él "dispuso casarla como en efecto se casó con el susodicho Andrés [...], ofreciéndole para este efecto, aunque verbal, por razón de dicho desmérito su dote, además de pagarle sus crecidas soldadas”, todo lo cual estaba aún sin entregar en $1784 \stackrel{31}{ }$.

Pero no siempre los casados de esta manera acababan formando una auténtica comunidad de intereses a la hora de reclamar judicialmente lo acordado. No, en ocasiones estos enlaces matrimoniales eran una tapadera, una de las muchas fórmulas empleadas por los señores, para proseguir con una relación prohibida y evitar en la medida de lo posible el escándalo público. Para ello, era necesario un “cabrón”, como, por ejemplo, Lucio Santiso, vecino de san Xoán de Bouzoa, mayor de sesenta años, marido de la antigua criada del cura de Dozón, María de Fontao, quien cansado ya de su papel, la denuncia en julio de 1780 por sus continuas y reiteradas "ausencias de mi casa y compañía para la del dicho cura y otras partes a donde se le antoja, deteniéndose a ocho días, a quince y todo y más tiempo que le parece, sin volver a mi competencia, ni atender al gobierno y cuidado de mi casa y bienes. Y aunque sobre ello la reprendí varias veces [...], lejos de moderarse cada día es peor, tratándome de malas palabras y poniéndome violentamente las manos encima". Y todo porque "le doy poco asenso, motivo de ser mayor de edad y ella de mucho menos” $\underline{32}$.

No obstante, y a tenor de la información disponible, todo apunta a que el matrimonio no parece haber contribuido a poner fin a la relación de las criadas con el servicio doméstico. Esto nos lleva a preguntarnos si sus respectivos enlaces nupciales habrían supuesto o no para ellas una verdadera promoción social. Y es que el mencionado Andrés do Campo trabajaba como criado cuando aceptó la propuesta de casarse con Gabriela do Vilar. Por su parte, Domingo Antonio Toxo y Francisca Bravo, vecinos de santa María de Rendal, declaran en 1782 haberse conocido cuando ambos estaban sirviendo en la misma casa, allá por 1749, haberse casado en 1759 siendo todavía criados en ella, y llevar en la misma veintitrés años desempeñando respectivamente las funciones de mayordomo y ama de gobierno; en total, treinta y tres años vinculados al servicio doméstico. Por lo demás, no es seguro que las mujeres de Bartolomé García, vecino san Xulián da Veiga en 1701, o de José de Trabada, vecino a su vez de san Pedro de Castelo en 1769, no continúen en el oficio cuando ambos aparecen al lado de éstas en los tribunales reclamando las soldadas que les adeudaban sus antiguos señores $\underline{33}$. En este sentido, y a semejanza de lo ocurrido en otros contextos europeos, mucho nos tememos que las posibilidades de promoción social de las criadas vía matrimonial hayan sido bastante limitadas, quedando reducidas, -siempre en el mejor de los casos-, a casarse con individuos del mismo origen social que o bien seguían luego vinculados al servicio doméstico o bien pertenecían a los sectores más bajos del campesinado (Simonton, 1998, p. 99 y ss.; Wilcox, 1982, p. 31 y ss.; Gullickson, 1981, p. 188 y ss., y p. 196 y ss.). Unas posibilidades de promoción que, por otro lado, serían tanto más difíciles de conseguir cuanto más baja fuese la posición social de su señor en el reducido y exclusivo mundo de las elites de la Galicia interior.

\section{A modo de conclusión}

En este trabajo hemos tratado de profundizar y ampliar nuestros conocimientos sobre la composición, las características y el funcionamiento del servicio doméstico rural de la Galicia del Antiguo Régimen. Para ello, hemos tomado como ejemplo lo sucedido a los criados del clero secular de la Galicia interior, dado que a pesar del escaso peso que este grupo tenía en la estructura social de la zona, se beneficiaba, como el resto de las elites locales, del trabajo de un gran número de sirvientes (tablas 1 y 2). Muchos de los aspectos relativos a ellos, sea en lo referido a su origen social, consideración laboral, jerarquía interna o peso del género en la distribución y asignación de tareas, son muy parecidos a los imperantes en otras partes de Europa. Por esta razón, si a 
continuación tuviésemos que destacar alguno de sus rasgos más característicos y definitorios, nos centraríamos cuando menos en tres de ellos.

Primero, -y atendiendo al humilde origen social de los criados-, en la existencia de una auténtica "circulación de jóvenes" de abajo arriba en el seno de la estructura social. Esto es, de una circulación que los llevaba desde los grupos sociales más desposeídos del campesinado hasta los hogares de los sectores más pudientes de la sociedad rural. En esta tesitura, todo apunta a que en la Galicia interior el servicio doméstico habría funcionado como un mecanismo que servía para atenuar y, en cierto modo, para compensar, las enormes desigualdades sociales que allí existían. Habría actuado pues como un elemento que propiciaba la estabilidad social, al igual a como por las mismas fechas lo hacía en otras áreas regionales del norte de la Península Ibérica donde también predominaba la pequeña propiedad campesina, abundaban los criados, las familias complejas, y se practicaba un reparto hereditario no igualitario, tal es el caso, por ejemplo, de lo sucedido en los territorios más septentrionales del viejo reino de Navarra (Mikelarena, 1995, p. 269). La otra cara de la moneda a este nivel la encontramos sin embargo en aquellas tierras altas de la España interior, en la sierra de Alcaraz, por ejemplo, donde la abundancia de familias nucleares y la gran propiedad agrícola se combinaban para dar vida a un servicio doméstico compuesto casi en exclusiva por hombres -en el 85 \% de las ocasiones-, que vivían en sus propios hogares, o en los de sus padres, al tiempo que trabajaban en aquellas tareas agrícolas y ganaderas de carácter extensivo que dicha gran propiedad requería para su buen funcionamiento. Su origen humilde y la naturaleza de esas tareas nos indica que la mencionada "circulación de jóvenes" estuvo ausente de este mundo. Frente a ella y a sus beneficios, lo que aquí acontecía era una explotación sistemática del potencial productivo de los individuos pertenecientes a los sectores sociales más humildes en beneficio de un reducido grupo de poderosas familias; una explotación que, grosso modo, se desarrollaba sobre la base de unas relaciones clientelares y oligárquicas que contribuían a marcar y a acentuar las diferencias sociales (González García, 2000, pp. 217-221).

Segundo, en la estrecha relación que el servicio doméstico rural de la Galicia interior demuestra haber tenido con la micromovilidad geográfica y la movilidad campo-ciudad. Una relación de la que se desprende la existencia en este ámbito de redes parentales, sociales y laborales que funcionaban en su propio y particular beneficio y que habrá que investigar en futuros trabajos. En todo caso, la mera evidencia de esa existencia apunta a que los criados fueron un colectivo perfectamente integrado en la sociedad rural de la época. Nada indica que viviesen, -como sí parece ocurría en determinadas zonas de Inglaterra por las mismas fechas-, de espaldas o al margen de la misma y de sus valores sociales o morales (Laslett, 1980, pp. 217-249).

Tercero, en la difícil promoción social de las criadas a través del matrimonio. Una cuestión que nos remite al viejo problema de si en la Galicia rural del Antiguo Régimen hubo o no algo parecido a un life-cycle service al estilo anglosajón. A favor del mismo hablan aquellas mujeres que afirman haber dejado el oficio al casarse o el hecho de que el $82 \%$ de las criadas que reclamaban sus soldadas estuviesen solteras en el mismo momento de presentarse ante el tribunal ${ }^{34}$. En su contra lo hacen, sin embargo, aquellas jóvenes que no abandonaron el servicio doméstico después de haberse casado, los largos años de trabajo que decían haber pasado en él, y su humilde extracción social. La combinación de estos tres factores nos permite comprender que aunque estas jóvenes hubiesen empezado a servir a los nueve o diez años, a duras penas habrían podido llegar a casarse antes de cumplir los 2627 años, que era la edad media de contraer matrimonio para todas aquellas mujeres que se encontraban en condiciones de hacerlo sin mayores problemas. Este, obviamente, no era el caso de nuestras criadas, la mayoría de las cuales acabaron ayudando a engrosar el porcentaje de soltería definitiva femenina, que en este ámbito rondaba el $20 \%$ en 1787.

En suma, si bien el matrimonio pudo haber supuesto una mejora relativa de las condiciones de vida de estas jóvenes, ello no significa que en su caso fuese siempre acompañado de una verdadera promoción social. Por lo demás, todo apunta a que la posible existencia de un life-cycle service habría sido parcial y limitada, y a que estaría condicionada tanto por las circunstancias materiales y sociales de las criadas como por la serie de circunstancias socioeconómicas y familiares que configuraban el contexto histórico que imperó en las comarcas rurales de la Galicia interior entre 1700 y 1825. 


\section{Notas}

1 Archivo Histórico Diocesano de Lugo, (en adelante A.H.D.L.), Razón Universal de las piezas eclesiásticas del Obispado de Lugo, 1755.

$\underline{2}$ La edad media de los eclesiásticos ha sido calculada a partir de manejo de la información contenida en la Relación de la Visita Pastoral realizada por el Obispo de Lugo, don Lucas Busto de la Torre a todas las parroquias de la diócesis, 1703,conservada en el A.H.D.L.

$\underline{3}$ En el libro 3, título 2, canón 1, de las Constituciones sinodales de Lugo, hechas y promulgadas por don Matías Moratinos Santos en 1669, editadas en 1675 y en vigor durante todo el siglo XVIII, se indica que los curas no deberán tener viviendo y trabajando consigo a mujeres o criadas menores de los 40 años, véanse en el AH.D.L.

4 También, Novísima Recopilación de las leyes de España, 1805, libro X, título XI, ley X.

$\underline{5}$ A modo de ejemplo, véase A.H.D.L., Fondo de Pleitos Civiles, Santalla, mazo 1, n 4; A.H.D.L., Fondo de Pleitos Civiles, Cotos de Lugo, mazo 42, nº 2.; A.H.D.L., Fondo de Pleitos Civiles, Santalla, mazo 1, nº 2.

$\underline{6}$ Ejemplos de ello en A.H.D.L., Fondo de Pleitos Civiles, Aguiar, mazo 9, nº 14; y Cotos de Lugo, mazo 7, $\mathrm{n}^{\circ} 11$.

7 A.H.D.L., Fondo de Pleitos Civiles, Cotos de Lugo, mazo 7, n 11. Más ejemplos en Fondo de Pleitos Civiles, Aguiar, mazo 9, n 14; y Abeancos, mazo 11, nº 7.

$\underline{8}$ En este sentido, a comienzos del XVII se había prohibido ya la contratación de los criados por días, estableciéndose desde entonces el cómputo del tiempo trabajado en meses, Novisima Recopilación de las Leyes de España, 1805, libro VI, título XVI, ley 4.

9 Novisima Recopilación de las Leyes de España, 1805, libro VI, título XVI, libro 1.

10 Un buen ejemplo de ello, A.H.D.L., Fondo de Pleitos Civiles, Ferreira y Ferreirua, mazo 4, nº 8.

11 Ejemplos de ello en A.H.D.L., Fondo de Pleitos Civiles, Picato, mazo 7, nº 28; Picato, mazo 3, $n^{\circ}$ 8; Abeancos, mazo 8, no 10; Taboada, mazo 2, n 22; o Saviñao, mazo 9, nº 19.

12 Véase por ejemplo, A.H.D.L., Fondo de Pleitos Civiles, Abeancos, mazo 8, $n^{\circ}$ 10; Ulloa, mazo 6, $n^{\circ}$ 3; Santalla, mazo 4, no 21; Taboada, mazo 2, no 11; Cotos de Lugo, mazo 7, n 11.

13 Véase por ejemplo, A.H.D.L., Fondo de Pleitos Civiles, Abeancos, mazo 10, n 6; Chantada, mazo 7, $\mathrm{n}^{\circ}$ 2; Abeancos, mazo 10, nº 20.

14 Véase por ejemplo, A.H.D.L., Fondo de Pleitos Civiles, Abeancos, mazo 10, $\mathrm{n}^{\circ}$ 20; Santalla, mazo 1, $\mathrm{n}^{\circ} 2$; Ferreira y Ferreirua, mazo 4, no 8; Cotos de Lugo, mazo 27, nº 12; Cervantes, mazo 9, $n^{\circ} 2$.

15 A.H.D.L., Fondo de Pleitos Civiles, Aguiar, mazo 5, nº 24.

16 A.H.D.L., Fondo de Pleitos Civiles, Saviñao, mazo 7, nº 28.

17 A.H.D.L., Fondo de Pleitos Civiles, Páramo y Goldrame, mazo 3, nº 8.

18 Véase Archivo Histórico Provincial de Ourense (en adelante A.H.P.O.), Catastro de Ensenada, legajo 622. En la misma línea, véase también la declaración de Jacinto González, labrador, vecino de la feligresía de Vilamarín, A.H.P.O., Catastro de Ensenada, legajo 3472.

19 Véase A.H.D.L., Fondo de Pleitos Civiles, Neira de Jusá, mazo 2, nº 25. Igualmente, A.H.D.L., Fondo de Pleitos Civiles, Gomelle, mazo 1, $\mathrm{n}^{\circ} 4$.

20 Respectivamente Archivo Histórico del Reino de Galicia (en adelante A.H.R.G.), Catastro de Ensenada, respectivamente, legajos 1409, 1346 y 1352.

$\underline{21}$ Véase, A.H.P.O., Catastro de Ensenada, respectivamente, legajos 3472/3; 622 y 2670; y 2903/4. 
22 Respectivamente, A.H.R.G., Catastro de Ensenada, legajo 1409; A.H.P.O., Catastro de Ensenada, legajo $2903 / 4$.

$\underline{23}$ A.H.D.L., Fondo de Pleitos Civiles, Saviñao, mazo 13, nº 1.

$\underline{24}$ Novísima Recopilación de las Leyes de España, Madrid 1805, libro X, título XI, ley X y ley XI.

$2 \underline{5}$ Respectivamente, A.H.D.L., Fondo de Pleitos Civiles, Ulloa, mazo 6, nº 28; Ulloa, mazo 7, nº 20.

$\underline{26}$ Un buen ejemplo de ello, A.H.D.L., Fondo de Pleitos Civiles, Cotos de Lugo, mazo 45, nº 11.

27 Respectivamente, A.H.D.L., Fondo de Pleitos Civiles, Abeancos, mazo 11, nº 7; Neira de Jusa, mazo 2 , nº 25.

$\underline{28}$ En el mismo sentido, María Rosa Fernández, vecina de san Vicente de Argozón, quien en 1724 reconocía haber accedido a tener esos tratos con su señor, A.H.D.L., Fondo de Pleitos Civiles, Navego, mazo 4, nº 11.

29 A.H.D.L., Fondo de Pleitos Civiles, Cotos de Lugo, mazo 7, n 15 . En el mismo sentido, Cotos de Lugo, mazo $9, n^{\circ} 2$.

$\underline{30}$ A.H.D.L., Fondo de Pleitos Civiles, Cotos de Lugo, mazo 27, no 12.

31 A.H.D.L., Fondo de Pleitos Civiles, Aguiar, mazo 5, nº 24.

32 A.H.D.L., Fondo de Pleitos Civiles, Taboada, mazo 2, nº 31.

33 Véase respectivamente, A.H.D.L., Fondo de Pleitos Civiles, Abeancos, mazo 10, nº 6; Cervantes, mazo 9, nº 2; Santalla, mazo 13, $\mathrm{n}^{\circ} 2$.

34 María Sánchez, vecina de santo Tomé de Castro, declara que los problemas con su señor se iniciaron cuando éste supo “... que yo tenía tratado disponer de mi persona en el estado del matrimonio, y que de resulta no le podía servir...”, véase A.H.D.L., Fondo de Pleitos Civiles, Abeancos, mazo 8, n 10. Casos semejantes en A.H.D.L., Fondo de Pleitos Civiles, Paramo y Goldrame, mazo 3, nº 8; y Cotos de Lugo, mazo 42, n 2.

\section{Bibliografía}

Barreiro Mallón, B. (1973). La Jurisdicción del Xallas en el siglo XVIII. Población, Sociedad y Economía. Santiago de Compostela: Universidade de Santiago.

Berkner, L. K. (1972). The Stem Family and the developmental Cycle of the Peasant Household: An EighteenthCentury example. The American Historical Review, 77 (2, April) 398-419. doi: https://doi.org/10.2307/1868698

Comas D’Argemir, D. (1988). Household, Family and Social Stratificaction: Inheritance and Labour Strategies in Catalan village, XIXth-XXth centuries. Journal of Family History, 13, 1, 150-157.

Da Molin, G. (1990). Family Forms and Domestic Service in Southern Italy from Seventeenth to the Nineteenth Centuries. Journal of Family History, 415 (4), 503-527. doi: https://doi.org/10.1177/036319909001500408

Devine, T. M. (1984). Scotish Farm- System in the Agricultural Revolution. En T. M. Devine (Ed.), Farms Servants and Labour in Lownland Scotland, 1770-1914 (pp. 1-9). Edinburg: John Donald Publishers LTD.

Dopico, F. \& Rowland, R. (1990). Demografía del Censo de Floridablanca. Una aproximación. Revista de Historia Económica, VIII, 3, 591-619. doi: https://doi.org/10.1017/S0212610900002391

Dubert, I. (1992a). Historia de la Familia en Galicia durante la Época Moderna, 1550-1830. A Coruña-Sada: Edicións do Castro.

Dubert, I. (1992b). El fenómeno urbano en la Galicia interior. Características económicas y demográficas del ámbito semiurbano, Obradoiro de Historia Moderna, 1, 13-45. Recuperado de: http://www.usc.es/revistas/index.php/ohm/article/view/590/581 
Dubert, I. (2001). Attraction urbaine et dynamiques migratoires du service domestique en Galice, 1752-1924. Annales de Démographie Historique, 1, 155-176. doi: https://doi.org/10.3917/adh.101.0155

Dubert, I. (2009). La desaparición del servicio doméstico en la Galicia rural al término del Antiguo Régimen. En J. J. Bravo Caro \& J. Sanz Sampelayo (Ed.). Población y grupos sociales en el Antiguo Régimen (pp. 515-528). Vol. 1. Málaga: Universidad de Málaga.

Dubert, I. (2015). Ilegitimidad, matrimonio y mercados de trabajo femeninos en la Galicia interior, 1570-1899. Obradoiro de Historia Moderna, 24, 49-86. doi: https://doi.org/10.15304/ohm.24.2827

Febrero, J. (1806). Febrero reformado y comentado, o Librería de Escribanos que compuso José Febrero. 7 Volúmenes. Madrid: Imprenta de Benito García y Compañía.

García González, F. (2000). Las estrategias de la diferencia. Familia y reproducción social en la Sierra (Alcaraz, siglo XVIII), Madrid: Ministerio de Agricultura y Pesca.

Gullickson, G. L. (1981). The Sexual Division Labour in Cottage Industry and Agriculture in the Pays de Caux: Auffay, 1750-18650. French Historical Studies, vol. 12, 177-200. doi: https://doi.org/10.2307/286476

Iglesias Blanco, A. S. (2004). A casa de Xunqueiras nos séculos XVIII e XIX. Contribución ó estudo das economías fidalgas. Valga: Plana Artes Gráficas.

Jonhson, M. (1984). Domestic Work in Rural Iceland: an historical overview. En Long, N. (Ed.). Family and Work in Rural Societies (pp. 160-175). London and New York: Tavistock Publications.

Kussmaul, A. (1981). Servants in husbandry in Early Modern England. Cambridge: Cambridge, U.P.

Laslett, P. (1980). The bastardy prone sub-society. En P. Laslett et al. (Ed.). Bastardy and its Comparative History (pp. 217-249). London: Edward Arnold LTD.

Laslett, P. (1988). Servi e servizio nella structura sociale europea. Quaderni Storici, 68, (2), 345-354.

Lee, W. R. (1990). Women's Work and the Family: Some Demographic Implications of Gender-Specific Rural Work Patterns in XIX ${ }^{\text {th }}$-Century Germany. In P. Hudson et al. (Eds.). Women's Work and the Family Economy in historical perspective (pp. 50-76), Manchester: Manchester U. P.

Migués, V. (2002). As terras, as pousas e os vinculeiros. A fidalguía galega na época moderna. A Coruña- Sada: Edicións do Castro.

Mikelarena, F. (1995). Demografía y familia en la Navarra tradicional. Pamplona: Gobierno de Navarra.

Mikelarena, F. (1997). Las características de la familia troncal pirenaica española: su relación con las economías agrarias y con los regímenes demográficos. En I. Rowland \& R. Moll (Eds.), La Demografía y la Historia de la Familia (pp. 207-225). Murcia: Universidad de Murcia.

Moriceau, J.-M. (1994). Les fermiers de l'Île-de-France, XV $V^{e}$-XVIII ${ }^{e}$ Paris : Fayard.

Novísima Recopilación de las leyes de España, 1805, Madrid.

Orr, A. (1984). Farm Servants and Farm Labour in the Forth Valley and South-East Lowlands. In T. M. Devine (Ed.), Farms Servants and Labour in Lownland Scotland, 1770-1914 (pp. 29-55). Edimburg: John Donald Publishers LTD.

Presedo Garazo, A. (1999). Estructura, productividade e rendementos agrícolas da explotación campesiña na Galicia interior: o partido xudicial de Arzúa, 1750-1860. SEMATA. Ciencias Sociais e Humanidades, 9, $245-277$.

Presedo Garazo, A. (2009). Una poderosa élite local en Galicia durante la época moderna: el cero secular de origen hidalgo. En E. Soria Mesa \& R. Molina Recio (Eds.), Las élites en la época moderna: la monarquía española. Familia y redes sociales (pp. 325-337). Volumen 2. Córdoba: Universidad de Córdoba. 
Rey Castelao, O. \& Rial García, S. (2010). Historia das mulleres en Galicia. Idade Moderna. Santiago de Compostela: Xunta de Galicia-Nigratrea.

Roigé i Ventura, X. (1999). La herencia difícil. Estrategias económicas y transmisión patrimonial en el Priorat (Cataluña, siglos XIX-XX). En M. González Portilla y K. Zarraga (Eds.), Pensamiento demográfico, coyuntura y microanálisis (pp. 716-724), Zarautx: Universidad del País Vasco.

Saavedra, P. (2002). Una nueva mirada sobre la historia rural de la montaña lucense. En C. J. Fernández Cortizoy D. González Lopo (Eds.). Universitas. Homenaje a Antonio Eiras Roel (pp. 397-409). Tomo 1. Santiago: Universidade de Santiago de Compostela.

Salinari, G. (2004). Anatomia di un gruppo senza storia: i domestici a Firenze (1800-1875). Polis. Ricerche e studi su società e politica in Italia, 18, 2004, 47-75.

Sarti, R. (2015). Servo o padrone o della (in)dipendenza: I teoria I dibattiti. Bolonia: Scienza Politica.

Simonton, D. (1998). A History of European Women's Work. 1700 to the Present. London-New York: Routledge.

Sobrado Correa, H. (1992). Aproximación al fenómeno migratorio de la Galicia interior del Antiguo Régimen. La Tierra de Castroverde, 1700-1850. En A. Eiras Roel (Ed.). Aportaciones al estudio de la emigración gallega. Un enfoque comarcal (pp. 139-153). Santiago de Compostela: Xunta de Galicia.

Sobrado Correa, H. (2001a). La ciudad de Lugo en el Antiguo Régimen, siglos XVI-XIX. Lugo: Deputación de Lugo.

Sobrado Correa, H. (2001b). La Tierra de Lugo en la Edad Moderna. Economía campesina, familia y herencia, 1550-1860. A Coruña: Fundación Barrie de la Maza.

Tilly, L. A., Scott, J. W. \& Cohen, M. (1980). Women's Work and the European Fertility Patterns. In R. Rotberg \& T. K. Rabb (Eds.). Marriage and Fertility. Studies in Interdisciplinary History (pp. 219-249) Princeton-New Jersey: Princeton U.P.

Wilcox, P. (1982). Marriage and Domestic Service in Victorian Cambridge. Local Population Studies, 29, 19-35. 